\title{
OPTIMALISASI DIABETES SELF MANAGEMENT EDUCATION (DSME) DENGAN DUKUNGAN KELUARGA TERHADAP PENCEGAHAN KAKI DIABETES DI KOTA BIMA
}

\author{
Nurul Jannah*, Ayudiah Uprianingsih \\ STIKES Yahya Bima \\ e-mail: nuruljannah140594@gmail.com*
}

\begin{abstract}
Failure to manage diabetes occurs due to patient non-compliance in implementing therapy, controlling risk factors, low knowledge and family involvement in caring for diabetes sufferers. Patient diabetics are risk for diabetic foot ulcers. Diabetic foot ulcer problems are a chronic complication and can lead to physical disabilities. This study was a quasi-experimental study with a non-equivalent control group design where the study used pre-post-test and cluster sampling. Data were collected through questionnaires and observation sheets. The results showed $p$ value $=0.000(p<0.05)$ means diabetes self management education with family centered care could prevent the occurrence of diabetic foot ulcers. Improving the quality of life of diabetics can be done with good self-management to avoid complications that can worsen the condition. There is no best educational program if it is not accompanied by compliance, commitment and family support in carrying out treatment.
\end{abstract}

Keywords: Diabetes Self Management Education, DSME, family centered care,Diabetic foot ulcer

\begin{abstract}
ABSTRAK
Ketidakberhasilan dalam penanganan diabetes terjadi karena ketidakpatuhan penderita dalam menjalakan terapi, mengendalikan faktor resiko, rendahnya pengetahuan dan keterlibatan keluarga dalam merawat penderita diabetes. Penderita diabetes beresiko mengalami ulkus kaki diabetik. Masalah ulkus kaki diabetik merupakan komplikasi kronik dan dapat mengakibatkan cacat fisik. Penelitian ini adalah penelitian quasi ekperimen dengan desain non equivalent control group design dimana penelitian menggunakan pre test - post test dan menggunakan cluster sampling. Data dikumpulkan melalui kuisioner dan lembar observasi. Hasil dalam penelitian menunjukannilai $\mathrm{p}=0.000(\mathrm{p}<0,05)$ artinya bahwa diabetes self management education dengan dukungan keluarga dapat mencegah terjadinya ulkus kaki diabteik. Penigkatan kualitas hidup penderita diabetes dapat dilakukan dengan manajemen diri yang baik untuk menghidari dari komplikasi yang dapat memperburuk kondisi. Tidak ada program edukasi yang terbaik jika tidak diiringi dengan kepatuhan, komitmen dan dukungan keluarga dalam menajalankan pengobatan.
\end{abstract}

Kata kunci: Diabetes Self Management Education, DSME, Dukungan Keluarga, Ulkus kaki diabetik

\section{PENDAHULUAN}

Diabetes merupakan masalah epidemi global yang bila tidak segera ditangani secara serius akan mengakibatkan peningkatan dampak kerugian ekonomi yang signifikan. Penyakit diabetes mellitus sangat berpengaruh terhadap kualitas sumber daya manusia dan berdampak pada peningkatan biaya kesehatan yang cukup besar.Oleh karenanya semua pihak,baikmasyarakat maupun pemerintah, seharusnya ikut serta secara aktif dalam usaha pengendalian penyakit Diabetes Mellitus, khususnya dalam upaya pencegahan. Kurangnya manajemen kesehatan dalam mengatasi diabetes mellitus dapat menmperbuuk kondisi penderita yang beujung pada komplikasi. Ketidakberhasilan dalam penanganan diabetes terjadi karena ketidakpatuhan penderita dalam menjalakan terapi, mengendalikan faktor resiko, rendahnya pengetahuan dan keterlibatan keluarga dalam merawat penderita diabetes. Penderita diabetes beresiko mengalami ulkus kaki diabetik. Masalah ulkus kaki diabetik merupakan komplikasi kronik dan dapat mengakibatkan cacat fisik. Penderita diabetes melitus beresiko $15 \%$ mengalami ulkus kaki diabetik (Munali et al., 2019). Ulkus kaki diabetik merupakan salah satu komplikasi utama yang paling merugikan dan paling serius dari diabetes melitus, $10 \%$ sampai $25 \%$ dari pasien diabetes berkembang menjadi ulkus kaki diabetik dalam hidup mereka (Fernando et al., 2014). Prevalensi penderita ulkus kaki diabetik sekitar 15\% (Sulistyowati, 2015) Kurangnya pengetahuan dan kesadaran penderita dan keluarga menyebabkan penderita diabetes mengalami luka gangren yang berat sehingga sering harus dilakukan amputasi. Pemberdayaan penderita diabetes mellitus memerlukan partisipassi aktif pasien, keluarga dan masyarakat 
International Diabetes Federation Atlas 2017 melaporkan bahwa epidemi Diabetes di Indonesia masih menunjukkan kecenderungan meningkat. RISKESDAS memperlihatkan peningkatan angka prevalensi Diabetes yang cukup signifikan, yaitu dari 6,9\% di tahun 2013 menjadi 8,5\% di tahun 2018. Data Jaminan Kesehatan Nasional (JKN) juga menunjukkan peningkatan jumlah kasus dan pembiayaan pelayanan Diabetes di Indonesia dari 135.322 kasus dengan pembiayaan Rp 700,29 Milyar di tahun 2014 menjadi 322.820 kasus dengan pembiayaan $\mathrm{Rp} 1,877$ Trilliun di tahun 2017 (DEPKES, 2018). Penyaktit diabetes mellitus termasuk 10 penyakit terbanyak di NTB pada tahun 2017. Penyakit diabetes mellitus merupakan penyakit tidak menular yang memberikan sumbangsi penyebab kematian hampir $70 \%$ di dunia. Pada penderita DM banyak yang mengeluhkan terjadinya ulkus diabetik sehingga diabetes mellitus menjadi penyebab terjadinya amputasi kaki pada penderita diabetes mellitus.

Diabetes Self Mangement Education (DSME) mengacu pada dukungan yang diperlukan untuk implementasi dan mempertahankan keterampilan dan perilaku koping yang dibutuhkan untuk menajemen diri secara berkelanjutan (Powers et al., 2017). Pendekatan secara individu dalam penanggulangan Diabetes Mellitus lebih diarahkan pada pendekatan terhadap keluarga karena keluarga merupakan penyedia pelayanan kesehatan utama bagi individu yang menderita penyakit kronis (Hasbi, 2012). Integrasi self care model dan family centered nursing merupakan suatu program yang memberdayakan anggota keluaraga melalui pendidikan kesehatan dan pelatihan yang diberikan oleh perawat kepada anggota keluarga yang bertanggung dalam merawat anggota keluarga penderita diabetes mellitus.

Pencegahan supayatidak terjadi amputasi sebenarnya sangat sederhana, tetapi sering terabaikan. Dukungan keluarga adalah hal terpenting untuk menentukan tingkat kepatuhan upaya pengobatannya selain dari kemampuan individu dalam menjalankan penatalaksanaan diabetes mellitus. Tujuan penelitian ini untuk mengetahui pengaruh dari optimalisasi Diabetes Self Management Education (DSME) dengan dukungan keluarga terhadap pencegahan ulkus kaki diabetik pada penderita diabetes mellitus. Hasil penelitian ini akan memberikan informasi bahwa dukungan keluarga dalam program DSME adalah bagian yang tidak dapat terpisahkan dari keberhasilan dalam perawatan pasien diabetes.

\section{METODE}

Penelitian ini adalah penelitian kuantitatif yang dilakukan di kota bima. Rancangan penelitian ini adalah quasi experimental dengan desain non equivalent control group design dimana penelitian menggunakan pre test - post test. teknik pengambilan sampel secara clustersampling. Pada penelitian ini dibagi menjadi 2 kelompok yaitu 50 responden pada kelompok kontrol dan 50 responden pada kelompok intervensi. Kriteria inklusi pada penelitian ini adalah klien diabetes mellitus tipe II yang bersedia menjadi responden penelitian. Kriteria eksklusi adalah klien diabetes mellitus tipe II dengan ulkus kaki diabetik dan responden yang menolak menjadi subjek penelitian. Data dikumpulkan melalui kuisoner dan lembar observasi. Analisa data yang digunakan adalah uji mann whitney.

\section{HASIL}

\section{Analisis Univariat}

Tabel 1 Karakteristik responden pada kelompok intervensi dan kelompok kontrol.

\begin{tabular}{lllll}
\hline Karakteristik & \multicolumn{3}{l}{ Intervensi } & \multicolumn{2}{l}{ Kontrol } \\
\cline { 2 - 5 } responden & $\mathrm{n}$ & $\%$ & $\mathrm{n}$ & $\%$ \\
\hline Umur & & & & \\
$35-59$ & 28 & $56 \%$ & 27 & $54 \%$ \\
$60-79$ & 22 & $44 \%$ & 23 & $46 \%$ \\
\hline Jenis kelamin & & & & \\
Perempuan & 36 & $72 \%$ & 39 & $78 \%$ \\
Laki-laki & 14 & $28 \%$ & 11 & $22 \%$ \\
\hline Pendidikan & & & & \\
Tidak sekolah & 6 & $12 \%$ & 7 & $14 \%$ \\
SD & 9 & $18 \%$ & 8 & $16 \%$ \\
SMP & 7 & $14 \%$ & 8 & $16 \%$ \\
SMA & 13 & $26 \%$ & 12 & $24 \%$ \\
PT & 15 & $30 \%$ & 15 & $30 \%$ \\
\hline Pekerjaan & & & & \\
Tidak bekerja & 22 & $44 \%$ & 35 & $70 \%$ \\
Swasta & 1 & $2 \%$ & 0 & $0 \%$ \\
Wiraswasta & 14 & $28 \%$ & 10 & $20 \%$ \\
PNS & 3 & $6 \%$ & 4 & $8 \%$ \\
Petani & 10 & $20 \%$ & 1 & $2 \%$ \\
\hline Status & & & & \\
Kawin & 49 & $98 \%$ & 49 & $98 \%$ \\
Tidak kawin & 1 & $2 \%$ & 1 & $2 \%$ \\
\hline Lama menderita & & & & \\
$<1$ tahun & 5 & $10 \%$ & 10 & $20 \%$ \\
1-5 tahun & 41 & $82 \%$ & 37 & $74 \%$ \\
$>5$ tahun & 4 & $8 \%$ & 3 & $6 \%$ \\
\hline
\end{tabular}

Berdasarkan tabel 1 diatas, Sebagian responden pada kelompok intervensi memiliki umur 35-59 tahun (56\%), jenis kelamin perempuan (72\%), pendidikan perguruan tinggi $(30 \%)$, tidak memiliki pekerjaan (44\%), status kawin (98\%), lama menderita 1-5 tahun (82\%). Sedangkan sebagian responden pada kelompok control memiliki umur 35-59 tahun (54\%), jenis kelamin perempuan $(78 \%)$, pendidikan perguruan tinggi $(30 \%)$, tidak memiliki pekerjaan (70\%), status kawin (98\%), lama menderita 1-5 tahun $(82 \%)$. 


\section{Analisis Bivariat}

Tabel 2.Pengaruh DSME dengan dukungan keluarga terhadap pencegahan ulkus kaki diabetik

\begin{tabular}{|c|c|c|c|c|}
\hline & Kelompok & $\mathrm{N}$ & $\begin{array}{l}\text { Median } \\
\text { (Min- } \\
\text { Max) }\end{array}$ & $\begin{array}{l}\mathrm{P} \\
\text { Valu } \\
\text { en }\end{array}$ \\
\hline \multirow{2}{*}{$\begin{array}{l}\text { Pencegah } \\
\text { an ulkus } \\
\text { kaki } \\
\text { diabetik }\end{array}$} & Intervensi & 50 & $\begin{array}{ll}65 & (39- \\
88) & \end{array}$ & 0.000 \\
\hline & Kontrol & 50 & $\begin{array}{l}31 \quad(28- \\
83)\end{array}$ & \\
\hline $\begin{array}{l}\text { Uji Mar } \\
\text { intervensi }\end{array}$ & $\begin{array}{l}\text { Whitney. } \\
\text { 2,14; kelo }\end{array}$ & Iean & $\begin{array}{l}\text { rank } \mathrm{ke} \\
\operatorname{trol} 28,86\end{array}$ & mpok \\
\hline
\end{tabular}

Berdasarkan tabel 2 diatas, Nilai mean pada kelompok intervensi 72,14, sementara pada kelompok control 28,86. Hasil uji Mann whitney menunjukan nilai $\mathrm{p}=0.000(\mathrm{p}<0,05)$. Hasil penelitian menunjukan bahwa pada kelompok intervensi yang diberikan perlakuan DSME dengan dukungan keluarga memiliki pengaruh yang lebih besar terhadap pencegahan ulkus kaki diabetic dibandingkan dengan kelompok lontrol. Disimpulkan bahwa secara statistic ada perbedaan yang bermakna pencegahan ulkus kaki diabetic pada kelompok intervensi dan kelompok kontrol.

\section{PEMBAHASAN}

Pelaksanaan DSME dengan dukungan keluarga dapat menurunkan terjadinya ulkus kaki diabetic. Menurut Funnell (2011) DSME merupakan suatu proses berkelanjutan yang dilakukan untuk memfasilitasi pengetahuan, keterampilan, dan kemampuan klien DM untuk melakukan perawatan mandiri.

Pelaksanaan DSME terdiri dari 4 sesi, dalam pelaksanaannya tidak hanya memberikan penyuluhan tetapi juga mengajarkan keterampilan mendemonstarsikan perawatan kaki. Perawatan kaki yang baik benar dapat mencegah dari terjadinya ulkus kaki diabetik. Kurangnya pengetahuan dan kesadaran penderita menyebabkan randahnya prilaku pencegahan ulkus kaki diabetik

Menurut IWGDF (2015) komponen perawatan kaki terdiri dari 6 komponen yaitu inspeksi kaki harian, menjaga kaki bersih dan kering, menjaga kelembutan kaki memotong kuku yang sejajar dengan ujung jari dan lurus, perlindungan dan pertolongan pertama pada trauma kaki, pemilihan sepatu dan kaos kaki. Dalam penelitian ini komponen yang kurang dapat dilaksanakan oleh reponden yaitu perlindungan dan pertolongan pertama pada trauma kaki. Sehingga kontinuitas pengajaran DSME tetap harus dilaksanakan untuk kualitas hidup pasien diabetes yang lebih baik.

Pada kelompok intervensi Pasien diabetes yang mendapat dukungan keluarga dalam perawatannya dapat meningkatkan keberhasilan dalam menjalakan terapi, mengendalikan factor resiko, melaksanakan perawatan kaki, sehingga memiliki perilaku yang baik dalam pencegahan ulkus kaki diabetik. Praktik keluarga sebagai pusat keperawatan (family centered nursing), didasarkan pada prespektif bahwa keluarga unit dasar untuk keperawatan individu dari anggota keluarga. Potensi dan keterlibatan keluarga menjadi makin besar, ketika salah satu anggota keluarganya memerlukan bantuan terus menerus karena masalah kesehatannya bersifat kronik. Pemberdayaan penderita diabetes mellitus memerlukan partisipassi aktif pasien, keluargadan masyarakat

Dalam pelaksanaan DSME pada kelompok kontrol. Pasien tidak didampingi oleh keluarga dalam menerima pengajaran materi DSME. Pasien yang tidak mendapatkan dukungan keluarga selama menjalankan perawatan memiliki kesadaran dan prilaku yang kurang baik dalam manajemen kesehatan diri. Pasien merasa putus asa sehingga kurang semangat dalam menjalankan perawatan. Pengajaran DSME yang diberikan tidak terserap baik dan kurang diimplementasikan dalam kehidupan sehari-hari. Perawatan kaki yang menjadi dasar perilaku pencegahan terjadinya ulkus kaki tidak dilakukan. Kurangnya motivasi diri dan dukungan keluarga dari pasien menyebabkan kurangnya prilaku dalam pencegahan ulkus kaki diabetik.

DSME merupakan suatu proses pemberian edukasi kepada klien mengenai aplikasi strategi perawatan diri secara mandiri untuk mengoptimalkan kontrol metabolik, mencegah komplikasi, dan memperbaiki kualitas hidup klien DM (Fan and Sidani, 2017).

Faktor yang memengaruhi kepatuhan menurut Niven (2008) meliputi pendidikan, akomodasi, modifikasi faktor lingkungan dan social, perubahan model terapi, meningkatkan interaksi professional kesehatan dengan klien, pengetahuan, usia dan dukungan keluarga. Pada kelompok perlakuan dilakukan DSME dimana setiap selama dua minggu responden dikunjungi peneliti sebanyak 4 kali dalam 2 minggu, hal ini sesuai dengan salah satu faktor yang memengaruhi kepatuhan menurut Niven (2008) yaitu meningkatkan interaksi professional kesehatan dengan klien. Pelaksanaan DSME dapat meningkatkan pengetahuan klien DM dan keluarganya tentang DM dan pengelolaannya serta meningkatkan status psikososial klien DM dan keluarganya berkaitan dengan kepercayaan dan sikap terhadap program pengobatan dan mekanisme koping. DSME bukan hanya sekedar menggunakan metode penyuluhan baik langsung maupun tidak langsung tetapi sudah berkembang dengan mendorong partisipasi dan kerjasama klien DM dan keluarganya. DSME yang efektif harus mengintegrasikan praktik dan pendidikan kesehatan yan dapat di implementasikan (Chrvala, Sherr and Lipman, 2016).

Dukungan keluarga merupakan bagian dari klien yang paling dekat dan tidak dapat dipisahkan. Dengan dukungan tersebut akan menimbulkan 
kepercayaan klien DM untuk mengelola penyakitnya lebih baik, serta klien mau menuruti saran saran yang diberikan oleh keluarga untuk menunjang pengelolaan penyakitnya. Keluarga akan dapat mengingatkan klien jika keluarga juga memahami tentang DM dan penatalaksanaanya. Pada kelompok kontrol penyuluhan kesehatan yang dilakukan hanya diikuti oleh klien saja tanpa ada pendampingan dari keluarga sehingga keluarga tidak bisa berpartisipasi dalam pengelolaan DM. Keluarga juga tidak mengetahui bagaimana penatalaksanaan DM yang benar karena tidak mengikuti penyuluhan kesehatan yang diberikan. Peneliti berpendapat keluarga sangat berperan terhadap keberhasilan DSME karena dengan keterlibatan keluarga maka klien dapat mengotrol pengelolaan DM secara mandiri.

\section{KESIMPULAN}

Pelaksanaan DSME sebaiknya melibatkan dukungan keluarga dalam menjalankanya. Dukungan keluarga merupakan bagian dari klien yang paling dekat dan tidak dapat dipisahkan. Keterlibatan keluarga dalam perawatan pasien mentukan keberhasilan dalam pencegahan terjadinya ulkus kaki diabetik serta dapat meningkatkan kualitas hidup penderita diabetes. Saran untuk peneliti selanjutnya yaitu mengkaji tingkat terjadinya ulkus kaki diabetic pada penderita diabetes yang menjalankan DSME dengan dukungan keluarga dan tanpa dukungan keluarga. DSME merupakan proses kolaboratif dan berkelanjutan yang dimaksudkan untuk memfasilitasi pengembangan pengetahuan, keterampilan, dan kemampuan yang dibutuhkan untuk manajemen diri diabetes yang sukses. Keterlibatan penderita dalam melaksanakan DSME dapat memaksimalkan intervensi dalam perawatan. DSME secarasignifikan meningkatkan kemampuan pasiendiabetes dalam melakukan perawatan kakimandiri dan mampu mengurangi kejadian kakidiabetes non ulkus.

\section{DAFTAR PUSTAKA}

1. Chrvala, C. A., Sherr, D. and Lipman, R. D. (2016) 'Diabetes self-management education for adults with type 2 diabetes mellitus: A systematic review of the effect on glycemic control', Patient Education and Counseling. Elsevier Ireland Ltd, 99(6), pp. 926-943. doi: 10.1016/j.pec.2015.11.003.

2. Damayanti, S. and Rahil, N. H. (2018) 'Efektivitas Diabetes Self Management Education ( Dsme ) Terhadap Kejadian Kaki Diabetik Non Ulkus ( Dsme ) on Non Ulcer Diabetic Foot', Jurnal Medika Respati, 13, pp. 19-28.
3. Depkes RI. 2018. Riset Kesehatan Dasar. Jakarta: Badan Penelitian dan pengembangan Kesehatan Kementrian Kesehatan RI.

4. Fan, L. and Sidani, S. (2017) 'Effectiveness of Diabetes Self-management Education Intervention Elements: A Meta-analysis', Canadian Journal of Diabetes. Elsevier, 33(1), pp. 18-26. doi: 10.1016/S1499-2671(09)310059.

5. Fernando, M. E. et al. (2014) 'Plantar pressure in diabetic peripheral neuropathy patients with active foot ulceration, previous ulceration and no history of ulceration: A meta-analysis of observational studies', PLoS ONE, 9(6). doi: 10.1371/journal.pone.0099050.

6. Funnell, M. M., Brown, T. L., Childs, B., Haas, L. B. and Hosey, G. M. (2011) 'National Standards for Diabetes Self-', 34. doi: 10.2337/dc11-S089.

7. Haas, L. et al. (2012) 'National standards for diabetes self-management education and support', Diabetes Care, 35(11), pp. 2393-2401. doi: 10.2337/dc12-1707.

8. Hasbi, M. (2012) 'Analisis Faktor yang Berhubungan dengan Kepatuhan Penderita Diabetes Melitus dalam Melakukan Olahraga di Wilayah Kerja Puskesmas Praya Lombok Tengan', Fakultas Ilmu Keperawatan Universitas Indonesia.

9. International Diebetes Federation. (2017). IDF Diabetes Atlas -Eighth edition 2017.

10. IWGDF (2015) 'The 2015 IWGDF Guidance documents on prevention and management of foot problems in diabetes: development of an evidence-based global consensus on the Diabetic Foot The 2015 IWGDF Guidance documents on prevention and management of foot problems in diabete'.

11. Kementrian Kesehatan RI (2018) Riset Kesehatan Dasar Badan Penelitian dan Pengembangan Kesehatan Tahun 2018

12. Kusnanto (2012) 'Model Self Care Management-Holistic Psychospiritual Care Terhadap Kemandirian, Glukosa Darah dan HbA1C Penderita Diabetes Melitus Tipe 2 (Self Care Management-Holistic Psychospiritual Care on Independence, Glucose Level, and HbA1C of Type 2 Diabetes Melli', Jurnal Ners, 7(2), pp. 99-106.

13. Munali et al. (2019) 'Edukasi Kesehatan: Perawatan Kaki Terhadap Pengetahuan, Sikap 
dan Tindakan Pencegahan Ulkus Kaki Diabetik', journal Ners, 8(1).

14. Nejhaddadgar, N. et al. (2019) 'Effectiveness of self-management program for people with type 2 diabetes mellitus based on PRECEDE PROCEED model', Diabetes and Metabolic Syndrome: Clinical Research and Reviews. Diabetes India, 13(1), pp. 440-443. doi: 10.1016/j.dsx.2018.08.016.

15. Niven, N. (2008) Psikologi Kesehatan: Pengantar untuk Perawat dan Profesional Kesehatan lain (terjemahan). Kedua. Jakarta: EGC.
16. Powers, M. A. et al. (2017) 'Diabetes Selfmanagement Education and Support in Type 2 Diabetes', The Diabetes Educator, 43(1), pp. 40-53. doi: 10.1177/0145721716689694.

17. Sulistyowati, D. A. (2015) 'Proses Penyembuhan Ulkus Diabetik Di Ruang Melati I Rsud Dr. Moewardi Tahun 2014', Jurnal Ilmu Kesehatan Kosala, 3(1), pp. 83-88. Available at: http://ejurnal.akperpantikosala.ac.id/index.php/ji k/article/viewFile/47/28. 